\title{
PERAN GURU SD DALAM MEMBANGUN KARAKTER BANGSA
}

\section{SINDI DWIRANTI}

\author{
Program Studi Pendidikan Guru Sekolah Dasar \\ Fakultas Keguruan dan Ilmu Pendidikan \\ Universitas Nahdlatul Ulama Sidoarjo \\ Email : dwisindi8@gmail.com
}

\section{Pengantar}

A. Arti Pendidikan Karakter

Di zaman globalisasi sekarang dengan kemajuan IPTEK (Ilmu Pengetahuan Teknologi) yang berkembang di Indonesia merupakan suatu hal yang dapat memberikan berbagai pengaruh dalam dunia pendidikan. Perkembangan IPTEK dapat memberikan ruang yang efisien terhadap penerapan pendidikan di Indonesia. Pendidikan yang diterapkan di Indonesia memiliki berbagai kemajuan seiring dengan perkembangan IPTEK. Di Indonesia sistem pendidikan nasional telah diatur dalam UU No. 20 Tahun 2003. Pendidikan dibedakan menjadi 3 macam, yaitu : pendidikan formal, pendidikan non formal, dan pendidikan informal.

Bukan hanya itu, di Indonesia pun menerapkan pendidikan karakter. Apakah pendidikan karakter itu? Pendidikan karakter adalah pendidikan yang membangun moral anak, membentuk karakter anak.

Pendididkan karakter menurut Suyanto (2009) mendefinisikan karakter sebagai cara berpikir dan berperilaku yang menjadi ciri khas individu untuk hidup dan bekerja sama baik dalam lingkup keluarga,masyarakat, bangsa maupun Negara.

Menurut kamus psikologi, karakter adalah kepribadian ditinjau dari titik tolak etis atau moral, misalnya kejujuran seseorang, dan biasanya berkaitan dengan sifatsifat yang relatif tetap (Dali Gulo, 1982: p.29).

Pendidikan karakter dapat diartikan sebagai the deliberate us of all deminsions of school life to foster optimal character development (usaha kita secara sengaja dari seluruh dimensi kehidupan sekolah/ madrasah untuk membantu pembentukan karakter secara optimal. 


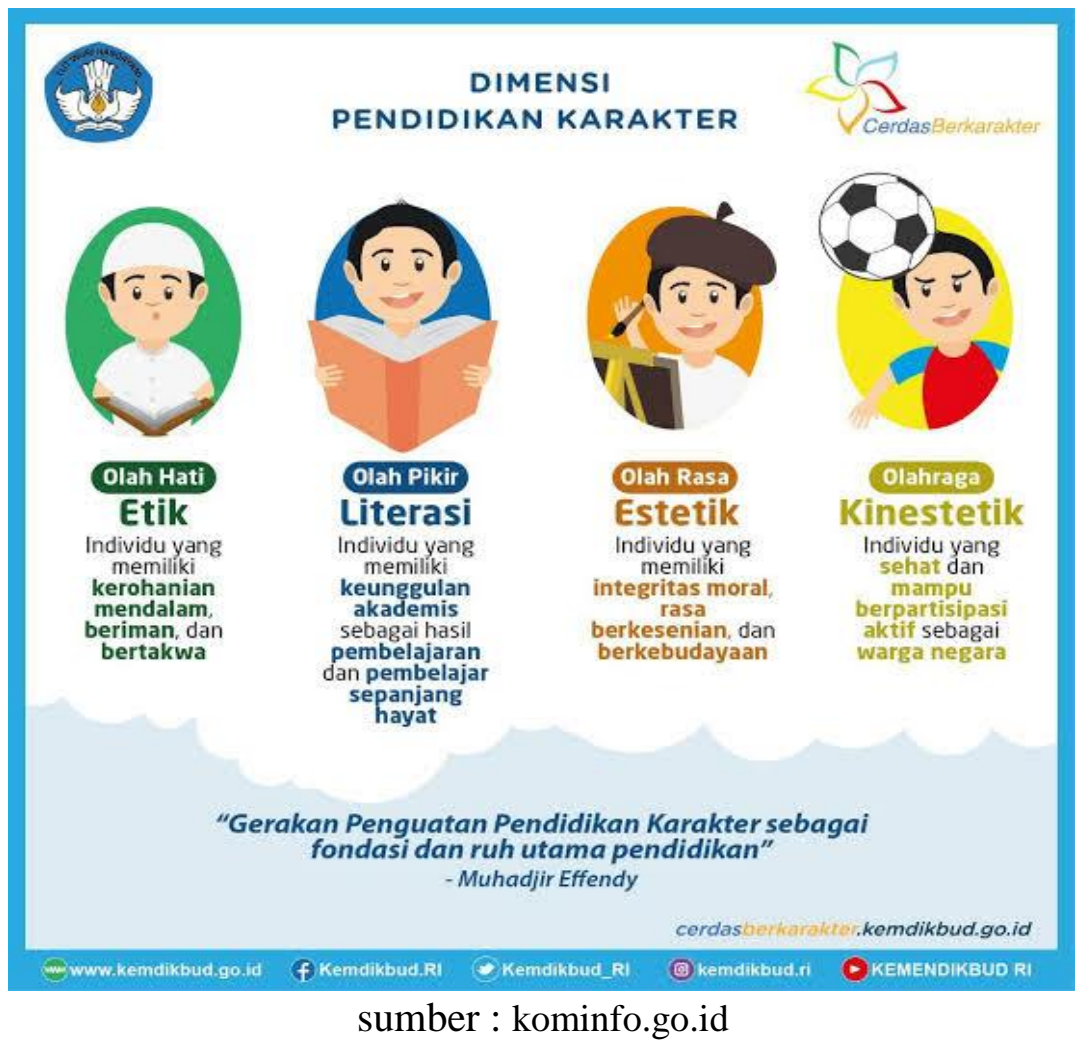

B. Pentingnya Pendidikan Karakter

Pendidikan karakter merupakan pendidikan yang megedepankan moral dari siswa, masyarakat suatu Negara harus memiliki moral yang baik, oleh sebab itu pendidikan karakter di Indonesi mulai dikembangkan sejak masa sekolah untuk memberikan karakter yang sesuai dengan kemampuan anak maupun sesuai dengan adat yang berlaku.

Pendidikan karakter juga merupakan upaya untuk meningkatkan sumber daya manusia, karena masyarakat yang berkarakter akan menjamin untuk meningkatkan kemajuan bangsa dalam berbagai hal. Misalnya seseorang yang memiliki jiwa yang jujur dan amanah akan mampu untuk dijadikan pemimpin suatu bangsa atau suatu instansi, bayangkan jika banyak masyrakat yang memiliki jiwa atau moral yang baik, maka Indonesia akan makmur, akan timbul rasa saling gotong royong. Oleh karena itu, pendidikan karakter sangat diperlukan. 


\section{Urgensi Pendidikan karakter}

Pengaruh globalisasi juga dapat memberikan dampak negatif, karena banyak budaya asing yang masuk dalam Indonesia, terkadang tidak sesuai dengan adat istiadat di Indonesia. Oleh karena itu, bangsa Indonesia harus dapat menyaring apa yang baik yang dapat digunakan, dan apa yang buruk bisa ditinggalkan.

Dampak dari globalisasi atau perkembangan IPTEK harus kita saring untuk dapat digunakan sebagai alat yang dapat memberikan dampak positif. Oleh karena itu maka penting untuk kita memperkokoh moral, dengan cara menerapkan pendidikan karakter yang diharapkan dapat menanamkan nilai-nilai moral untuk memperkuat bangsa.

Mengapa pendidikan karakter sangat dibutuhkan? Karena banyak anakanak yang belum mengerti akan apa yang baik untuk dirinya dan apa yang buruk. Banyak kasus anak-anak generasi z ini yang menguasai gadget menggukan internet untuk mengetahui berbagai hal, sehingga terkadang mereka tidak mengetahui itu baik atau tidak, mereka sibuk dengan dunia mereka yang menimbulkan sikap tidak saling peduli terhadap lingkungannya. Sebenarnya tidak semua hal yang ada di internet atau penggunaan gadget itu buruk atau berdampak negatif, tetapi terkadang orang tua tidak dapat mengawasi apa yang diakses oleh anak. Maka pendidikan karakter dan pendidikan informal juga sangat dibutuhkan.

Ditahun 2018 ini presiden Jokowi dan wakil presiden Jusuf kalla membentuk kebijakan pendidikan Penguatan Pendidikan Karakter (PPK) yang bertujuan untuk merubah cara berpikir, bersikap dan bertindak menjadi lebih baik.

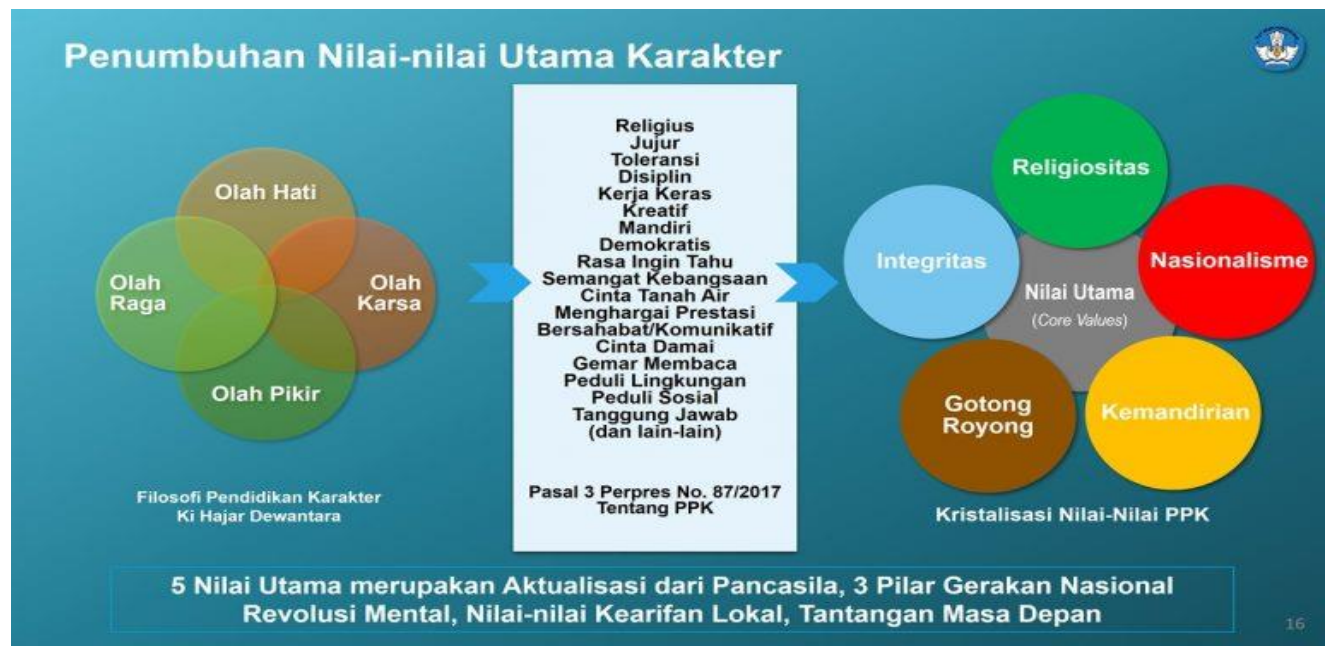

Sumber : cerdasberkarakter.kemendikbud.go.id 


\section{Ruang Lingkup dalam Pendidikan Karakter}

\section{A. Instansi atau sekolah}

Instansi atau sekolah merupakan sarana penunjang untuk penerapan pendidikan karakter. Pendidikan karakter diajarkan sejak SD hingga anak benar-benar memiliki karakter atau moral.

B. Pendidik atau guru SD

Sebenarnya semua guru dapat menerapkan pendidikan karakter terhadap siswanya, tetapi kali ini penulis membahas guru SD karena sekolah dasar adalah masa dimana pembentukan karakter sudah dapat dibentuk, dimana anak sudah mulai dapat diajak untuk berfikir akan dirinya, sudah mulai melakukan sesuatu yang ia inginkan dengan keunikannya masingmasing.

C. Murid SD

Dalam hal ini murid SD merupakan objek, dimana para guru menjadi pengarah bagi siwa-siswinya agar dapat menjadi generasi yang berkarakter, generasi yang dapat memimpin bangsa Indonesia.

\section{Implementasi Guru SD dalam Penerapan Pendidikan Karakter}

Banyak guru yang menerapkan pendidikan karakter. Contoh penerapanyya adalah dengan pendekatan yang meliputi pengintegrasian nilai dan etika dalam setiap mata pelajaran, nilai positif yang ditanamkan kepala sekolah, guru, dan orang tua, pembiasaan dan latihan, pemberian contoh teladan, penciptaan suasana berkarakter di sekolah dan pembudayaan.

Ada beberapa hal yang harus dimiliki oleh guru sebagai pendidik yang mengintegrasikan pendidikan moral dan karakter pada anak didiknya. Xie dan Zhang (2011) menyatakan bahwa seorang pendidik harus melakukan (1) cultivation a noble of mind dimana guru memenuhi kewajiban dan mencintai pekerjaan, serta memiliki karakter pribadi yang baik. (2) improving of teaching ability cara guru menerapkan pendidikan. (3) study of the theoris of education science mempelajari tentang teori pendidikan. (4) participation in the scientific research activity. (5) possession of management capability.

Dalam hal lain, ada beberapa guru yang berperan dalam hal pendidikan melalui pembangunan instansi yang dapat menunjang pendidikan karakter cotohnya adalah ibu Eryeka Wirawanti kelahiran Surabaya lulusan Universitas Negeri Surabaya dalam mengelola Madrasah Ibtidaiyah Progresif Bumi Sholawat yang telah berkiprah sejak tahun 2011 .

MI Progresif Bumi sholawat dibangun secara langsung karena awalnya bangunan tersebut merupakan sebuah pondok pesantren."Saya percaya pendidikan dibutuhkan oleh semua kalangan, khususnya ilmu dalam bidang agama. Oleh sebab 
itu, saya terus maju membangun sekolah meski banyak rintangan", ucap ibu Eryeka Wirawanti.

Contoh lainnya yaitu bapak mansyur, pendiri SD Antawirya. "Saya meyakini apapun yang kita lakukan untuk orang lain sebenarnya untuk diri kita sendiri. Kita melakukan untuk diri sendiri yang lebih baik akan timbul aura positif itulah yang bisa kita berikan. Karena saya disini bukan memberi tapi diberi. Yaitu dberi kesempatan untuk belajar untuk menjadi lebih baik lagi. Diberi kesempatan untuk ikut mendirikan dan mengelola SD ini. Oleh sebab itu, bagaimanapun rintangannya saya tidak akan menyerah untuk menghadapinya.", kata Bapak Mansyur.

Dari beberapa contoh tersebut merupakan bukti bahwa akan ada jalan untuk memberikan pendidikan yang terbaik bagi anak bangsa, dan diharapkan agar anakanak Indonesia dapat meneruskan perjuangan para guru terdahulu untuk membangun bangsa Indonesia yang lebih baik.

\section{Rangkuman}

Peran guru SD dalam pendidikan karakter merupakan salah satu tujuan para guru untuk memberikan yang terbaik terhadap bangsa ini dengan cara mendidik para siswa-siswi untuk dapat menjadi penerus sekaligus pelurus bangsa ini. Sejatinya guru memang mendedikasikan ilmunya kepada para siwanya maka mari kita hargai perjuangan yang telah dilakukan para guru, karna kita tak akan bisa mengetahui akan ilmu yang tak kita ketahui sebelumya.

\section{DAFTAR PUSTAKA}

Kominfo (2017,aug 17) penguatan pendidikan karakter jadi pintu masuk pembenahan pendidikan nasional. Retrieved 2018, dec 28. From https://kominfo.go.id/content/10111/penguatan-pendidikan-karakter-jadipintu-masuk-pembenahan-pendidikan-nasional/0/artikel_gpr

Hariyanto (2012,june 12) pengertian pendidikan karakter. Retrieved 2018, dec 28.

From https://belajarpsikologi.com/pengertian-pendidikan-karakter/

Kemendikbud (2018) penguatan pendidikan karakter. Retrieved 2018, dec 28. From https://cerdasberkarakter.kemendikbud.go.id/?page_id=132

Marysa, R., Hilal I., \& Agustina E.S. (2014). Pendidikan Karakter Pada Pembelajaran Bahasa Dan Sastra Indonesia Di Smpn 1 Gunung Sugih. Jurnal Kata (bahasa, sastra, dan pembelajarannya). 2 
Lestyarini, B. (2012). Penumbuhan semangat kebangsaan untuk memperkuat karakter Indonesia melalui pembelajaran bahasa. Jurnal pendidikan karakter, 2(3), 349 .

Qori'ah, S., Sholikhah, S.A., Purnomo, A., \& Rosyidah, E. (2017). MI Progresif Bumi Sholawat dengan Kebenaran Semua Pasti Ada Jalan. In Wirausaha Pendidikan Indonesia (Jilid 3). Sidoarjo: Unusida Press.

Maula, I., Mufidah, F.I., Rosyidah, E., \& Purnomo, A. (2017). SD Antawirya Islamic Javanese School Mother is Culture. In Wirausaha Pendidikan Indonesia (Jilid 1). Sidoarjo: Unusida Press. 